\title{
O processo de terceirização de serviços hoteleiros: Motivações e fundamentos teóricos
}

\author{
The process of outsourcing hotel services: \\ Motivations and theoretical foundations
}

\section{El proceso outsourcing de servicios de alojamiento: Marco teórico y razones}

\author{
Kawana Harue Sato ${ }^{1}$ \\ Tomas Sparano Martins ${ }^{2}$ \\ Heitor Takashi Kato ${ }^{3}$ \\ Roberta Rocha Rosa Martins ${ }^{4}$ \\ Eduardo Damião da Silva ${ }^{5}$
}

\begin{abstract}
Resumo: Este estudo discute o processo de terceirização em hotéis. O objetivo deste estudo foi verificar por que os hotéis terceirizam seus serviços e atividades, e como ocorre o processo de terceirização nos hotéis em Curitiba, na perspectiva das capacidades dinâmicas. Especificamente tomou-se como base o modelo teórico de Teece (2007) das microfundações das capacidades dinâmicas, na qual o autor propõe que a exploração dos limites organizacionais e a coespecialização fazem parte da capacidade dinâmica das organizações. Quanto à análise, utilizou-se a técnica da análise de conteúdo do tipo categorial em seis hotéis. Os resultados mostram que as decisões das terceirizações foram motivadas principalmente por razões financeiras, tais como a possibilidade de redução de custos e a melhoria do desempenho financeiro. Com relação ao processo de decisão da terceirização, observou-se que processos formalizados são adotados especialmente por hotéis pertencentes a redes. Hotéis independentes adotam processos mais informais na decisão da terceirização.
\end{abstract}

Palavras-chave: Terceirização; Hotéis; Processo; Capacidades dinâmicas; Coespecialização.

Abstract: This study discusses the process of outsourcing in hotels. The aim of this study was to determine why the hotels outsource their services and activities, and how the outsourcing process occurs in hotels in Curitiba, in the perspective of dynamic capabilities. Specifically we took as basis the theoretical model of Teece (2007) of the microfoundations of dynamic capabilities, in which the author proposes that the exploitation of organizational boundaries and coespecialization are part of the dynamic capability of organizations. Regarding the analysis, we used the technique of analyzing the content of categorical six

\footnotetext{
${ }^{1}$ Pontifícia Universidade Católica do Paraná. E-mail: kawana.sato@gmail.com

${ }^{2}$ Pontifícia Universidade Católica do Paraná. E-mail: tomas.martins@pucpr.br

${ }^{3}$ Pontifícia Universidade Católica do Paraná. E-mail: $\underline{\text { heitor.kato@pucpr.br }}$

${ }^{4}$ Pontifícia Universidade Católica do Paraná. E-mail: robertarosamartins@hotmail.com

${ }^{5}$ Pontifícia Universidade Católica do Paraná. E-mail: eduardo.damiao@pucpr.br
} 
hotels. The results show that the decisions of outsourcing were primarily motivated by financial reasons, such as the possibility of reducing costs and improving performance financier. In relation to the outsourcing decision process, it was observed that formalized processes are adopted especially by hotels that belong to chains. Independent hotels adopt more informal processes in the outsourcing decision.

Keywords: Outsourcing; Hotels; Process; Dynamic capabilities, Coespecialization.

Resumen: Este estudio analiza el proceso de externalización en los hoteles. El objetivo de este estudio fue determinar por qué los hoteles externalizar sus servicios y actividades, y cómo el proceso de externalización se produce en los hoteles en Curitiba, en la perspectiva de las capacidades dinámicas. En concreto, se tomó como base el modelo teórico de Teece (2007) de los microfundamentos de las capacidades dinámicas, en las que el autor propone que la explotación de los límites de la organización y coespecialization son parte de la capacidad dinámica de las organizaciones. En cuanto al análisis, se utilizó la técnica de análisis del contenido de categóricos seis hoteles. Los resultados muestran que las decisiones de externalización fueron motivados principalmente por razones financieras, tales como la posibilidad de reducir los costos y mejorar el rendimiento financiero. En relación con el proceso de toma externa, se observó que se adoptó procesos formalizados especialmente por hoteles que pertenecen a cadenas. Hoteles Independent adoptar procesos más informales en la decisión de outsourcing.

Palabras clave: Outsourcing; Hoteles; Procesos; Capacidades dinâmicas; Coespecialização.

\section{INTRODUÇÃO}

O contexto organizacional competitivo atual é caracterizado por rápidas e profundas mudanças. Essas mudanças acabam forçando as organizações a adotar posturas estratégicas ágeis e flexíveis, objetivando conquistar vantagens competitivas que garantam uma posição superior no mercado em relação aos concorrentes. Manter a vantagem competitiva é uma atividade estratégica dinâmica que nunca termina (Hung, Chung \& Lien, 2007). De maneira genérica, uma preocupação central da estratégia é manter o ajuste dinâmico entre o que uma empresa tem para oferecer e o que o ambiente quer.

Com a descoberta do potencial turístico do Brasil, várias empresas externas interessaramse em investir neste setor. A hotelaria hoje tem satisfeito à demanda dos novos segmentos de mercado, o que, ao mesmo tempo, propicia o surgimento de novas formas de turismo e diversifica o portfólio de serviços. A evolução da hotelaria na última década e sua ampla perspectiva de crescimento acompanham uma tendência verificada em todos os ramos e setores de negócios: a qualificação e especialização dos serviços prestados (Andrade, Brito \& Jorge, 2000).

Neste estudo, parte-se da premissa de que a administração das terceirizações nos empreendimentos hoteleiros constitui-se parte das capacidades dinâmicas organizacionais que possibilitam a empresa a explorar recursos organizacionais fora de seus limites. Ainda, Teece (2007) propõe em seu modelo que os processos para explorar fornecedores, selecionar os limites organizacionais e a coespecialização constituem-se em algumas das microfundações das capacidades dinâmicas. Considera-se ainda, que mudanças ambientais, neste caso a crise financeira e gripe H1N1, influenciam nesse processo. 
Para atingir os objetivos da presente pesquisa, serão apresentados tópicos teóricos sobre capacidades dinâmicas, terceirização e terceirização em hotéis.

\section{CAPACIDADES DINÂMICAS}

Teece, Pisano e Shuen (1997, p. 516), autores de um dos artigos mais referenciados no tema, definem capacidades dinâmicas como "a habilidade da firma para integrar, construir, e reconfigurar competências internas e externas para lidar com rápidas mudanças ambientais". Essa capacidade reflete a habilidade da firma em alcançar novas e inovadoras formas de vantagem competitiva.

Apesar do estudo de Teece, Pisano e Shuen (1997) ser o pioneiro e ter servido de base para estudos posteriores, diversas outras definições de capacidades dinâmicas podem ser encontradas na literatura, dentre eles a definição elaborada por Teece (2007, p. 1319), o qual afirma a Capacidade Dinâmica ser a capacidade de "identificar e moldar oportunidades e ameaças, aproveitar as oportunidades e manter competitividade por meio do reforço, combinação, proteção e, quando necessário, reconfiguração dos ativos tangíveis e intangíveis da organização".

Essa exploração de recursos externos, seja por meio da formação de alianças ou parcerias externas, pode favorecer a incorporação rápida de mudanças à organização. Mas, se por um lado ela facilita a adaptação organizacional às novas exigências ambientais, por outro lado, exige que as organizações desenvolvam habilidades para administrar os relacionamentos interorganizacionais, habilidade esta definida por Rodríguez-Días e Espino-Rodríguez (2006) como a capacidade relacional da organização.

Segundo Prahalad e Hamel (1990), o desenvolvimento das capacidades relacionais, particularmente a terceirização, é uma alternativa viável para as organizações que buscam a vantagem competitiva por meio do desenvolvimento das suas competências essenciais. Nesse mesmo sentido, Bolat e Yilmaz (2009) salientam que a terceirização de atividades que não são centrais para a organização permite concentrar esforços gerenciais em tarefas que realmente importam e que a própria empresa melhor executa. Esse foco pode melhorar os resultados organizacionais por meio da melhora de eficiência, melhor capacidade de inovação e melhora das habilidades nas atividades centrais.

\section{TERCEIRIZAÇÃO}

A terceirização pode ser caracterizada como um processo de transferência de determinadas funções internas (da empresa-origem) que podem ser desempenhadas por outras empresas (empresa-destino) (Brasil, 1993).

Para Leite (2004), a terceirização é vista como uma estratégia empresarial, uma espécie de desintegração vertical, que possibilita a concentração de esforços nas atividades-fim, deixando as atividades-meio a cargo de parceiros especializados que melhor exerçam suas funções e traduzam 
melhores resultados com ganhos efetivos para as duas partes. Transferindo para terceiros uma parte de suas atividades, a empresa pode transformar um custo fixo em custo variável. Além da diminuição dos gastos fixos, a empresa torna-se mais rápida e adaptável às mudanças ambientais.

De um modo geral a decisão pela terceirização de uma atividade, operação ou serviço é tomada em função da expectativa de melhora do desempenho da organização (Lilly et. al, 2005). Essa melhoria de desempenho pode estar associada ao aumento de foco da organização nas competências essenciais. De acordo com Gilley e Rasheed (2000), quando a organização decide pela terceirização da atividade ou serviço, o desempenho organizacional é melhorado por três razões principais: o foco nas competências centrais, a melhoria da qualidade dos serviços e a redução de custos.

\section{TERCEIRIZAÇÃO NO SEGMENTO HOTELEIRO}

Alguns autores como Lamminmaki (2011) afirmam que a natureza das atividades de operação dos hotéis faz com que estas sejam particularmente adequadas à terceirização. Algumas características particulares das operações hoteleiras fazem com que haja uma predisposição à terceirização. Tais características incluem a diversidade de atividades desenvolvidas, o alto grau de mão de obra associada a muitas atividades do hotel e a natureza volátil da demanda pelos serviços de hospedagem.

Alguns estudos sobre terceirização das atividades no segmento hoteleiro podem ser encontrados na literatura. Um deles, realizado com hotéis na Espanha por Espino-Rodríguez e Padrón-Robaina (2004), mostra que as operações de serviços mais terceirizadas são os serviços relacionados à lavanderia, segurança e vigilância, atividades de lazer, serviços de jardinagem, treinamento, sistemas de informação e limpeza. De acordo com o estudo realizado pelos autores os gestores hoteleiros gostariam de terceirizar mais operações, pois encontraram fornecedores com capacidade para oferecer bons serviços.

Por outro lado as operações que apresentam baixa tendência de serem terceirizadas são os serviços relacionados à recepção, reservas, área comercial e administração, uma vez que essas atividades são consideradas básicas para os hotéis. (Espino-Rodríguez \& Padrónrobaina, 2004).

Bolat e Yilmaz (2009) buscaram avaliar o impacto da terceirização no desempenho de empresas hoteleiras. Os autores argumentam que a terceirização melhora o desempenho organizacional quando implementada de modo eficiente e que a terceirização envolve um processo que influencia nessa performance. Assim, o desempenho superior nos hotéis pesquisados deve-se em parte pelo processo de planejamento e implantação do processo de terceirização. $O$ estudo foi baseado em dados survey de empresas hoteleiras na Turquia e os resultados indicaram que a terceirização levou a resultados positivamente significantes no que se refere à eficiência, produtividade, rentabilidade, qualidade, melhoramento contínuo, qualidade de vida no trabalho e níveis de responsabilidade social (Bolat \& Yilmaz, 2009). 


\section{METODOLOGIA}

O estudo possuiu delineamento de estudo de casos múltiplos, do tipo descritivo e comparativo, com abordagem predominantemente qualitativa. Quanto ao corte temporal foi um estudo longitudinal com corte transversal, pois se propôs a investigar o processo de terceirização de serviços durante o período de 2006 a 2010, o que permite verificar de que maneira a crise financeira de 2008 influenciou nas terceirizações. O nível de análise foi organizacional e a unidade de análise foi composta pelos dirigentes a nível estratégico das redes hoteleiras em Curitiba.

Como o objetivo deste estudo é avaliar as terceirizações de serviços nos hotéis, a seleção dos casos foi realizada com base em alguns critérios. Buscaram-se hotéis que possuíssem serviços terceirizados. Porém, consideraram-se adequados somente os hotéis que terceirizassem não somente o serviço de lavanderia, pois este é um serviço terceirizado pela grande maioria dos hotéis. Além disso, optou-se por priorizar os casos que possuíssem maior quantidade de serviços terceirizados.

A amostra foi composta por um total de 6 casos. Tais casos englobam todos os três tipos de hotéis (hotel de rede internacional, hotel de rede nacional e hotel independente), classificados em três categorias diferentes.

O método utilizado foi a análise de conteúdo. Segundo Bardin (2009), a análise de conteúdo refere-se a um conjunto de técnicas de análise das comunicações que usa procedimentos sistemáticos e objetivos para a descrição do conteúdo das mensagens. A técnica utilizada para a análise de conteúdo foi a análise categorial que, na visão de Bardin (2009), consiste no desmembramento do discurso em categorias de análise, em que os critérios de codificação estão orientados nos objetivos específicos da pesquisa, identificados nos discursos dos sujeitos entrevistados. As categorias de análise, deste ponto em diante, serão nomeadas códigos e sua aplicação às entrevistas chamadas de codificação.

A análise de conteúdo foi realizada como sugere Bardin (2009), utilizando-se três momentos para o seu desenvolvimento: a preparação dos dados e pré-análise; a exploração do material; e o tratamento dos resultados obtidos e interpretação.

\section{APRESENTAÇÃO E ANÁLISE DOS RESULTADOS}

No Brasil, o turismo é representativo para a economia, sua importância pode ser comprovada por meio da comparação de dados gerais do país com os dados referentes ao setor. A participação do turismo no PIB brasileiro é de 2,8\%, da demanda final é de 3,72\% e a participação da produção turística no valor bruto da produção total do país é de 3,23\%.

Especificamente, a oferta hoteleira no Brasil é composta essencialmente por hotéis independentes (92\% dos estabelecimentos), apenas $8 \%$, igualmente divididos, dos hotéis pertencem a redes nacionais ou internacionais (Jones Lang LaSalle Hotels, 2010). 
Após esta breve apresentação do contexto uma breve descrição dos seis casos é feito para então discutir semelhanças e diferenças:

1) Caso 1 - Hotel A: O Hotel A foi fundado em 2004. Pertence a uma rede internacional presente no mercado brasileiro desde 1998. A rede possui hotéis de diversas bandeiras, as quais abrangem diferentes públicos, ofertando desde hotéis econômicos até hotéis de luxo. O Hotel A enquadra-se na categoria superior. O hotel possui 96 apartamentos e oferece aos hóspedes piscina, Business Center, centro de convenções, estacionamento, fitness center, lavanderia, lobby bar, sauna a vapor, solarium e internet wi-fi nos apartamentos. Os serviços terceirizados no Hotel A são: mão de obra extra, monitoramento de internet, segurança alimentar, lavanderia e Business Center ${ }^{6}$.

2) Caso 2 - Hotel B: O hotel foi inaugurado em 2006 e pertence também a uma rede internacional. Trata-se da mesma rede do Hotel A. Possui 194 apartamentos e oferece aos hóspedes piscina, Business Center, centro de convenções, estacionamento com manobrista, fitness center, lavanderia, lobby bar, sala de massagem, sauna seca e internet wi-fi gratuita no apartamento. Os serviços terceirizados no Hotel B são: lavanderia, Business Center e estacionamento. Todos os três serviços são terceirizados desde a abertura do empreendimento.

3) Caso 3 - Hotel C: O Hotel C foi inaugurado em 2004 e pertence a uma rede nacional. Esta rede hoteleira iniciou suas operações em Curitiba no ano de 1981 e atualmente está presente em vários estados brasileiros do sul e sudeste. Possui hotéis de bandeiras diversificadas que se enquadram nas categorias econômico, superior e luxo. O Hotel C está classificado na categoria luxo, possui 84 quartos, sendo 4 suítes. O Hotel C oferece aos clientes bar com programação de música ao vivo, Business Center, Concierge on-line na recepção, estacionamento com manobrista, internet banda larga, restaurante, room service 24 horas e sala de ginástica. No Hotel C são terceirizados a lavanderia, o restaurante e o frigobar. A manutenção também passou pelo processo de terceirização no hotel, entretanto atualmente não se encontra mais terceirizada.

4) Caso 4 - Hotel D: O Hotel D pertence a uma rede nacional. A rede foi fundada em $1986 \mathrm{e}$ atualmente possui unidades hoteleiras em estados do sul do país. O Hotel D foi inaugurado recentemente, em 2008. Enquadra-se na categoria econômica e dispõe de 178 quartos. Oferece aos clientes estacionamento, restaurante, bar, Business Center, sala de ginástica, internet wireless e room service 24 horas. Neste hotel são terceirizados a lavanderia, o restaurante, a segurança, o Business Center e o frigobar.

5) Caso 5 - Hotel E: O Hotel E é um hotel independente e está classificado na categoria econômica. Foi fundado em 1978, possui 82 quartos e oferece aos clientes estacionamento, Business Center, sala para eventos, restaurante e internet wireless. Os serviços terceirizados no Hotel E são: lavanderia, panificação, contabilidade, serviços

\footnotetext{
${ }^{6}$ Considerou-se neste estudo Business Center a sala com equipamentos de informática para acesso dos hóspedes e clientes dos eventos, bem como o aluguel dos equipamentos a serem utilizados nos eventos.
} 
jurídicos e o suporte de informática.

6) Caso 6 - Hotel F: O Hotel F é um hotel independente. Foi inaugurado em 2001, possui 63 apartamentos e classifica-se na categoria econômica. O hotel oferece aos hóspedes café da manhã, estacionamento, traslado, Business Center e internet wireless. O hotel trabalha com a lavanderia, a panificação e o estacionamento terceirizados.

\section{ANÁLISE COMPARATIVA DOS CASOS}

Primeiramente apresenta-se o comparativo dos serviços terceirizados pelos seis hotéis. Num segundo momento apresenta-se a análise comparativa dos motivos associados à terceirização. Finalmente, faz-se uma análise dos processos de terceirização dos serviços e atividades dos seis hotéis entrevistados.

\section{SERVIÇOS TERCEIRIZADOS}

Realizou-se o estudo dos serviços terceirizados durante o período de 2006 a 2010 a fim de identificar quais mudanças ocorreram nas terceirizações. Tendo em vista que a crise financeira de 2008 provocou efeitos na economia brasileira em meados de 2009 e que a gripe H1N1 ocorreu no mesmo ano, a análise longitudinal das terceirizações revelaria mudanças ocorridas em 2009.

O resultado dessa análise é apresentado no Quadro 2 a seguir, o qual expõe todas as terceirizações adotadas em cada um dos hotéis entrevistados, no período de 2006 a 2010.

No Hotel A em 2006 eram terceirizados a lavanderia, o Business Center e a mão de obra extra. Tais serviços permanecem terceirizados nos anos seguintes. Já em 2008 uma nova atividade passou a ser terceirizada, a segurança alimentar. E em 2010 foi implantada a terceirização do monitoramento de internet. A razão da terceirização do monitoramento de internet foi principalmente os riscos à segurança do hotel, especialmente com relação à utilização da internet do hotel para aplicação de golpes. Assim, essa terceirização não foi influenciada pelos eventos crise financeira de 2008 e gripe H1N1.

Já no Hotel B são terceirizados a lavanderia, o estacionamento e o Business Center. Tais serviços são terceirizados desde 2006 e durante o período não houve novas terceirizações.

No que tange às terceirizações do Hotel A e Hotel B, por mais que os hotéis sejam da mesma rede, os serviços terceirizados são diferentes por possuírem necessidades distintas. Contudo, conforme apresentado na descrição dos casos, existem serviços que são terceirizados por uma determinação do Corporativo (Diretoria da rede), como no caso da segurança alimentar. Essas decisões devem ser implantadas obrigatoriamente em todos os hotéis da rede, conforme citado pelo gerente do Hotel A. Possivelmente, em virtude dessa determinação, a percepção do entrevistado do Hotel B foi diferente, não considerando tal serviço como sendo terceirizado. Mas não se pode descartar a hipótese de que o entrevistado, por seus valores, crenças e experiências, optou por resguardar essa informação no momento da entrevista. 
Quadro 1. Quadro comparativo dos serviços terceirizados no período de 2006 a 2010

\begin{tabular}{|c|c|c|c|c|c|}
\hline \multicolumn{6}{|c|}{ Serviços Terceirizados } \\
\hline \multirow[t]{2}{*}{ Hotel } & \multicolumn{5}{|c|}{ Períodos } \\
\hline & 2006 & 2007 & 2008 & 2009 & 2010 \\
\hline Hotel A & $\begin{array}{l}\text { - Lavanderia } \\
\text { - Business Center } \\
\text { - Mão de obra } \\
\text { extra }\end{array}$ & $\begin{array}{l}\text { - Lavanderia } \\
\text { - Business Center } \\
\text { - Mão de obra } \\
\text { extra }\end{array}$ & $\begin{array}{l}\text { - Lavanderia } \\
\text { - Business Center } \\
\text { - Mão de obra } \\
\text { extra } \\
\text { - Segurança } \\
\text { Alimentar }\end{array}$ & $\begin{array}{l}\text { - Lavanderia } \\
\text { - Business Center } \\
\text { - Mão de obra } \\
\text { extra } \\
\text { - Segurança } \\
\text { Alimentar }\end{array}$ & $\begin{array}{l}\text { - Lavanderia } \\
\text { - Business Center } \\
\text { - Mão de obra } \\
\text { extra } \\
\text { - Segurança } \\
\text { Alimentar } \\
\text { - Monitoramento } \\
\text { de Internet }\end{array}$ \\
\hline Hotel B & $\begin{array}{l}\text { - Lavanderia } \\
\text { - Estacionamento } \\
\text { - Business Center }\end{array}$ & $\begin{array}{l}\text { - Lavanderia } \\
\text { - Estacionamento } \\
\text { - Business Center }\end{array}$ & $\begin{array}{l}\text { - Lavanderia } \\
\text { - Estacionamento } \\
\text { - Business Center }\end{array}$ & $\begin{array}{l}\text { - Lavanderia } \\
\text { - Estacionamento } \\
\text { - Business Center }\end{array}$ & $\begin{array}{l}\text { - Lavanderia } \\
\text { - Estacionamento } \\
\text { - Business Center }\end{array}$ \\
\hline Hotel C & $\begin{array}{l}\text { - Lavanderia } \\
\text { - Restaurante }\end{array}$ & $\begin{array}{l}\text { - Lavanderia } \\
\text { - Restaurante }\end{array}$ & $\begin{array}{l}\text { - Lavanderia } \\
\text { - Restaurante } \\
\text { - Manutenção }\end{array}$ & $\begin{array}{l}\text { - Lavanderia } \\
\text { - Restaurante } \\
\text { - Frigobar }\end{array}$ & $\begin{array}{l}\text { - Lavanderia } \\
\text { - Restaurante } \\
\text { - Frigobar }\end{array}$ \\
\hline Hotel D & \multicolumn{2}{|c|}{ Hotel não existia } & $\begin{array}{l}\text { - Lavanderia } \\
\text { - Restaurante } \\
\text { - Frigobar } \\
\text { - Segurança } \\
\text { - Business Center }\end{array}$ & $\begin{array}{l}\text { - Lavanderia } \\
\text { - Restaurante } \\
\text { - Frigobar } \\
\text { - Segurança } \\
\text { - Business Center }\end{array}$ & $\begin{array}{l}\text { - Lavanderia } \\
\text { - Restaurante } \\
\text { - Frigobar } \\
\text { - Segurança } \\
\text { - Business Center }\end{array}$ \\
\hline Hotel E & $\begin{array}{l}\text { - Lavanderia } \\
\text { - Panificação } \\
\text { - Contabilidade } \\
\text { - Jurídico }\end{array}$ & $\begin{array}{l}\text { - Lavanderia } \\
\text { - Panificação } \\
\text { - Contabilidade } \\
\text { - Jurídico }\end{array}$ & $\begin{array}{l}\text { - Lavanderia } \\
\text { - Panificação } \\
\text { - Contabilidade } \\
\text { - Jurídico }\end{array}$ & $\begin{array}{l}\text { - Lavanderia } \\
\text { - Panificação } \\
\text { - Contabilidade } \\
\text { - Jurídico } \\
\text { - Suporte de } \\
\text { informática }\end{array}$ & $\begin{array}{l}\text { - Lavanderia } \\
\text { - Panificação } \\
\text { - Contabilidade } \\
\text { - Jurídico } \\
\text { - Suporte de } \\
\text { informática }\end{array}$ \\
\hline Hotel F & $\begin{array}{l}\text { - Lavanderia } \\
\text { - Panificação } \\
\text { - Estacionamento }\end{array}$ & $\begin{array}{l}\text { - Lavanderia } \\
\text { - Panificação } \\
\text { - Estacionamento }\end{array}$ & $\begin{array}{l}\text { - Lavanderia } \\
\text { - Panificação } \\
\text { - Estacionamento }\end{array}$ & $\begin{array}{l}\text { - Lavanderia } \\
\text { - Panificação } \\
\text { - Estacionamento }\end{array}$ & $\begin{array}{l}\text { - Lavanderia } \\
\text { - Panificação } \\
\text { - Estacionamento }\end{array}$ \\
\hline
\end{tabular}

Fonte: Elaboração própria.

Com relação ao Hotel C em 2006 encontravam-se terceirizados a lavanderia e o restaurante e em 2008 o hotel implantou a terceirização da manutenção. Conforme descrito anteriormente, essa terceirização foi encerrada em 2009, ano em que ocorreu também a implantação da terceirização do frigobar. Apesar de terem ocorrido em 2009, tais mudanças não se sucederam devido aos eventos ocorridos em 2009 (crise financeira e gripe H1N1). Como já comentado, o planejamento da terceirização do frigobar ocorreu antes dos eventos, e a anulação da terceirização da manutenção ocorreu por razões de inexistência de fornecedor especializado.

O Hotel D, inaugurado em 2008, iniciou com cinco serviços terceirizados: lavanderia, restaurante, frigobar, segurança e Business Center. Todos os serviços permaneceram terceirizados nos períodos seguintes, assim como não houve novas decisões de terceirização.

O Hotel E, em 2006, possuía os seguintes serviços terceirizados: a lavanderia, panificação, contabilidade e jurídico. Em 2009 o suporte de informática foi terceirizado. Apesar dessa mudança ter ocorrido no ano em que sentiram-se os efeitos da crise financeira de 2008 e da gripe H1N1, a terceirização não ocorreu como consequência disso. O serviço já era prestado por uma empresa 
externa, entretanto, foi em 2009 que ocorreu a formalização do serviço em contrato de terceirização.

O Hotel F mantém a terceirização da lavanderia, a panificação e o estacionamento. Esses serviços são terceirizados desde 2006 e permaneceram terceirizados até 2010. Não foram implantadas novas terceirizações, nem houve retorno de serviços para o hotel durante o período estudado.

Portanto, a crise financeira de 2008 e a gripe H1N1 não provocaram mudanças nas terceirizações dos hotéis entrevistados. Apesar disso, todos os hotéis apontaram que os dois eventos provocaram impactos no desempenho do hotel, uma vez que influenciou na demanda.

\section{MOTIVOS DA TERCEIRIZAÇÃO}

A identificação dos motivos da terceirização dos serviços e atividades nos hotéis foi realizada a fim de compreender de que maneira a terceirização contribui para a obtenção e manutenção da vantagem competitiva dos hotéis estudados. Além disso, as razões pela qual o hotel adotou a terceirização dos serviços, associado ao tipo de serviço, podem fornecer informações acerca da sua estratégia, especialmente voltadas à coespecialização e, portanto, relacionada à capacidade dinâmica.

O Quadro 3 revela os motivos que levaram à terceirização de cada atividade e em cada hotel entrevistado. Partindo-se de uma análise individualizada dos casos apresentados no Quadro 3 é possível avaliar os fatores motivadores mais relevantes dos hotéis entrevistados. Isto pode representar um reflexo da estratégia de cada hotel, especialmente quanto aos objetivos da terceirização.

A existência de fornecedor especializado apresenta-se em destaque no Hotel A. Tal motivo influenciou a decisão de quatro terceirizações. Os fatores custo e qualidade, por sua vez, influenciaram três terceirizações. Já o acesso à tecnologia/conhecimento foram as razões citadas de duas terceirizações. A alta demanda, a falta de estrutura física, a exigência do mercado, os golpes (riscos à segurança do hotel) e a necessidade de mão de obra especializada também foram mencionados pelo Hotel A como fatores motivadores, cada um sendo citado como fator motivador de apenas uma terceirização.

Logo, o Hotel A parece adotar uma posição estratégica de busca de fornecedores externos especializados para a realização de serviços/atividades muito específicas, às quais o hotel não teria condições de realizar sozinho, o que se pode chamar de coespecialização. Como afirma Kakabadse e Kakabadse (2000, p. 690) "talvez a maior vantagem da terceirização seja a plena utilização dos investimentos, inovações e capacidades dos profissionais especializados dos fornecedores externos". A realização do serviço por uma empresa especialista também garante a qualidade do serviço prestado, assim como há possibilidade de redução de custos, uma vez que o fornecedor alcança economias de escala por atender a outras empresas.

Por trabalharem com um quadro de mão de obra mais enxuto, os funcionários dos hotéis 
que não seguem o padrão luxo, atualmente desempenham diversas atividades, ou seja, além daquela que compete à sua função.

Devido a isso, atividades que exigem conhecimento e competências muito específicas e que necessitam de uma pessoa para cuidar exclusivamente de um serviço ou atividade, parece ter a tendência de ser terceirizadas. A característica específica da atividade exige muita atenção por parte do hotel, o que pode comprometer a qualidade do serviço e consequentemente o padrão de atendimento do hotel.

Resumidamente, serviços mais especializados exigem mão de obra capacitada para realizar o serviço. Assim parece que quanto maior a especialização do serviço, maior é a tendência para a terceirização do mesmo.

No Hotel B três motivos foram citados: o custo, a melhoria do desempenho financeiro e a necessidade de mão de obra. Cada motivo citado está relacionado às três terceirizações adotadas pelo hotel.

Apesar de serem três motivos diferentes, há uma relação direta entre eles. A melhoria do desempenho financeiro pode ser obtida em decorrência da redução de custos, assim como a contratação de mão de obra representa um aumento nas despesas. Desse modo, a estratégia de terceirização é vista como uma alternativa voltada para a redução de custos do empreendimento.

Já no Hotel $\mathrm{C}$ diversos motivos foram citados. $\mathrm{O}$ entrevistado apontou o fator custo como motivador de três terceirizações. A melhoria do desempenho financeiro, a necessidade de mão de obra e a necessidade de mão de obra especializada foram apontadas como motivadores de duas terceirizações. Outros cinco motivos também foram citados, cada um como motivador de uma terceirização: o acesso à tecnologia e conhecimento, a necessidade de estrutura física, a existência de fornecedor especializado, o porte do hotel e as questões tributárias.

Percebe-se também no Hotel $C$ a tendência de terceirização motivada pela redução de custos e pela possibilidade de melhoria do desempenho financeiro, pois os motivos apontados estão diretamente ligados ao custo, tais como necessidade de mão de obra e necessidade de mão de obra especializada. Entretanto, não se pode deixar de notar a presença da coespecialização, mesmo que em proporções bem menores.

Com relação ao Hotel D os motivos citados pelo entrevistado foram: categoria do hotel, custo, experiência da rede, foco nas competências essenciais, necessidade de mão de obra e necessidade de mão de obra especializada. Assim, percebe-se que o Hotel D busca, com a terceirização, principalmente reduzir custos e manter um quadro enxuto de funcionários, a fim de conservar o padrão econômico do hotel.

Tenta-se também manter o foco nas áreas essenciais (hospedagem e eventos), o que parece ser uma estratégia adotada pela rede para os hotéis que se enquadram na mesma categoria. Como a estratégia já é padronizada pela rede, a terceirização dos serviços ocorre principalmente em função de experiências desta com outros hotéis da mesma categoria. Sendo assim, a terceirização é adotada por se tratar de uma estratégia determinada pela rede, que, por sua vez, busca a terceirização para manter o padrão econômico dos hotéis. 
Quanto ao Hotel E o motivo referente à necessidade de mão de obra especializada mostrase em destaque, sendo citado como motivador de quatro das cinco terceirizações. Em seguida, é citado o porte do hotel, motivo de três terceirizações. Também foram citados o acesso à tecnologia e conhecimento, o custo, a existência de fornecedor especializado e a necessidade de mão de obra, cada um motivando duas terceirizações. Por fim, foi mencionada a necessidade de estrutura física como um motivo de uma das terceirizações.

Sendo o Hotel E de pequeno porte, este não possui condições financeiras para manter um profissional especializado dentro do hotel. Dessa forma, o mesmo busca a terceirização principalmente para suprir a necessidade de mão de obra especializada.

Apesar de contribuírem apenas para duas das cinco terceirizações, a existência de fornecedor especializado e o acesso facilitado ao conhecimento e às tecnologias pode estar associado a uma estratégia do hotel de buscar recursos complementares externos à organização. Tendo em vista que o hotel é independente, não estando ligada a nenhuma rede, sendo enquadrado na categoria econômica e de pequeno porte, não possui condições de operacionalizar todos os seus serviços internamente, necessitando complementar os seus recursos a partir de terceirizações.

O Hotel F mostrou-se motivado a terceirizar principalmente por questões de custo, falta de estrutura física e necessidade de mão de obra. A necessidade de mão de obra especializada e a qualidade também foram citadas pelo entrevistado, porém, motivando somente uma das três terceirizações. A falta de estrutura física é um aspecto delicado no Hotel F, sendo o único fator determinante para a terceirização do estacionamento.

Observando-se ainda o Quadro 3 pode-se verificar que a lavanderia é terceirizada por todos os hotéis entrevistados. Há também um consenso de que o custo é fator preponderante na terceirização da lavanderia.

O Business Center é terceirizado por três hotéis, correspondendo a dois de rede internacional e um de rede nacional. Muitos hóspedes e clientes de eventos possuem a necessidade de utilizar equipamentos de informática, por não estarem portando consigo tais equipamentos. Dessa forma o hotel tem a preocupação em atender esse público, oferecendo equipamentos modernos e atualizados, para suprir a necessidade dos clientes. Por este motivo, faz-se necessária a terceirização, pois para o hotel manter esses equipamentos atualizados requer altos investimentos.

Os hotéis independentes não terceirizam o Business Center apesar de ambos oferecerem equipamentos de informática aos hóspedes e um deles disponibilizar sala para eventos. Eles oferecem uma estrutura própria e mais simples do que as estruturas oferecidas pelos grandes hotéis pertencentes a redes. As salas de eventos são menores e adequadas para a realização de eventos de pequeno porte e reuniões.

Nota-se que o frigobar e o restaurante são terceirizados somente pelos hotéis de redes nacionais. Os hotéis internacionais mantem a área de alimentos e bebidas sobre responsabilidade do próprio hotel. Já nos hotéis independentes, a área de alimentos e bebidas não é terceirizada, pois não oferecem ao hóspede almoço e jantar, apenas o café da manhã. 
Quadro 2. Quadro comparativo dos serviços terceirizados e motivos da terceirização

\begin{tabular}{|c|c|c|c|c|c|c|c|c|c|c|c|c|c|c|}
\hline \multirow[b]{2}{*}{ Motivos da terceirização } & \multicolumn{14}{|c|}{ Serviços terceirizados } \\
\hline & 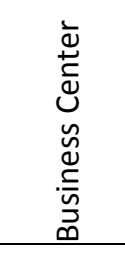 & $\begin{array}{l}\frac{0}{0} \\
\frac{\pi}{0} \\
. \frac{0}{\overline{0}} \\
\frac{0}{0} \\
\stackrel{ \pm}{0} \\
0 \\
\end{array}$ & 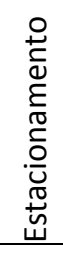 & 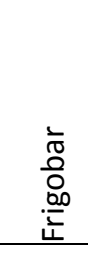 & $\frac{.0}{.0}$ & $\begin{array}{l}\frac{\pi}{2} \\
\frac{0}{2} \\
\frac{1}{0} \\
\frac{\pi}{0} \\
\frac{\pi}{1} \\
\end{array}$ & 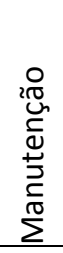 & 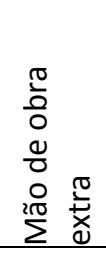 & 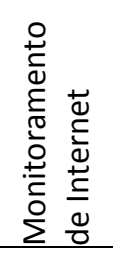 & 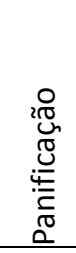 & 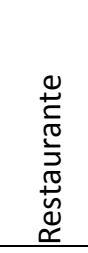 & 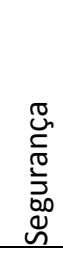 & 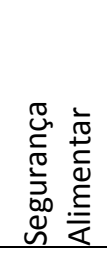 & 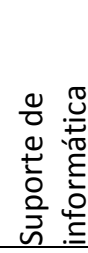 \\
\hline $\begin{array}{l}\text { Acesso à } \\
\text { tecnologia/conhecimento }\end{array}$ & $A$ & & & & $\mathrm{E}$ & $\mathrm{E}$ & & & & & $\mathrm{C}$ & & A & \\
\hline Alta demanda & & & & & & & & A & & & & & & \\
\hline Categoria do hotel & $\mathrm{D}$ & & & $\mathrm{D}$ & & $\mathrm{D}$ & & & & & D & $\mathrm{D}$ & & \\
\hline Custo & $A ; B ; D$ & & B & C; D & & $\begin{array}{l}\text { A; B; C; } \\
\text { D; E; F }\end{array}$ & & & A & $E ; F$ & $C ; D$ & $\mathrm{D}$ & & \\
\hline Estrutura física & & & $\mathrm{F}$ & & & $A ; E ; F$ & & & & & $\mathrm{C}$ & & & \\
\hline Exigência do mercado & $\mathrm{A}$ & & & & & & & & & & & & & \\
\hline $\begin{array}{l}\text { Existência de fornecedor } \\
\text { especializado }\end{array}$ & A & & & C & & $A ; E$ & & & A & $\mathrm{E}$ & & & A & \\
\hline Experiência da rede & $\mathrm{D}$ & & & $\mathrm{D}$ & & $\mathrm{D}$ & & & & & $\mathrm{D}$ & $\mathrm{D}$ & & \\
\hline $\begin{array}{l}\text { Foco nas competências } \\
\text { essenciais }\end{array}$ & $\mathrm{D}$ & & & $\mathrm{D}$ & & $\mathrm{D}$ & & & & & $\mathrm{D}$ & $\mathrm{D}$ & & \\
\hline Golpes & & & & & & & & & A & & & & & \\
\hline $\begin{array}{l}\text { Melhoria do desempenho } \\
\text { financeiro }\end{array}$ & B & & B & C & & B & & & & & C & & & \\
\hline $\begin{array}{l}\text { Necessidade de mão de } \\
\text { obra }\end{array}$ & $B ; D$ & & B & $C ; D$ & & $\begin{array}{c}\text { B; C; D; } \\
\text { F } \\
\end{array}$ & & & & $\mathrm{E}$ & $\mathrm{D}$ & $\mathrm{D}$ & & $\mathrm{E}$ \\
\hline $\begin{array}{l}\text { Necessidade de mão de } \\
\text { obra especializada }\end{array}$ & $A ; D$ & $\mathrm{E}$ & & $\mathrm{D}$ & $\mathrm{E}$ & $D ; E ; F$ & C & & & $\mathrm{E}$ & C; D & $\mathrm{D}$ & & \\
\hline Porte do hotel & & $E$ & & & & & & & & $\mathrm{E}$ & $\mathrm{C}$ & & & $\mathrm{E}$ \\
\hline Qualidade & & & & & & $A ; F$ & & & $\mathrm{~A}$ & & & & A & \\
\hline Questões tributárias & & & & & & & & & & & $\mathrm{C}$ & & & \\
\hline
\end{tabular}

\section{Fonte: Elaboração própria.}


As opiniões quanto à terceirização da área de alimentos e bebidas são divergentes. Há aqueles que consideram sua terceirização uma alternativa viável, entretanto, outros consideram um erro deixá-la sob a responsabilidade de terceiros. Os motivos dessa discussão são diversos.

De acordo com informações obtidas com um profissional do setor hoteleiro ${ }^{6}$, a área de alimentos e bebidas, quando bem administrada, pode trazer bons retornos financeiros para 0 hotel, podendo ser responsável por até $35 \%$ do seu faturamento. No entanto o setor pode também representar mais da metade dos gastos do hotel.

Além dos aspectos financeiros, considera-se que o setor de alimentos e bebidas é parte das atividades centrais de um hotel e, por isso, a qualidade desses serviços é indispensável, uma vez que refletirá imediatamente na imagem do hotel. ${ }^{7}$ Assim, acredita-se que a qualidade do serviço de alimentos e bebidas é melhor quando o próprio hotel se responsabiliza pelas atividades do setor de alimentos e bebidas.

A discussão envolve também outros aspectos além do financeiro, ela é em parte abordada no estudo de Hemmington e King (2000). Segundo os autores é raro hotéis terceirizarem todo o serviço de alimentos e bebidas. Normalmente há a preferência de manter o controle de áreas mais rentáveis tais como o serviço de café da manhã. Por outro lado os donos de restaurante estão interessados em assumir o serviço de café da manhã e preferem evitar a prestação do serviço de quarto.

Um aspecto importante que deve ser lembrado é que o café da manhã é um serviço importante para os hotéis, pois se torna uma estratégia de precificação para a maioria deles. Dessa maneira, a terceirização do café da manhã poderia corresponder a uma perda na capacidade e flexibilidade de negociação da hospedagem. A divisão das operações da área de alimentos e bebidas geralmente é fator gerador de tensão entre as partes, já que os donos de restaurante preferem assumir a função toda.

Portanto, é possível que hotéis pertencentes a redes internacionais não terceirizem os serviços de alimentos e bebidas por considerá-los essenciais para o hotel, além dos aspectos relacionados à qualidade do serviço. Também há de se considerar que tais hotéis são de maior porte, com um volume de vendas que também viabiliza as operações, aspecto citado pelo gestor do Hotel C. O estacionamento é terceirizado por um hotel de rede internacional e por outro hotel independente.

Nota-se, entretanto, que a decisão de terceirização por parte do Hotel B (rede internacional) foi realizada baseada no custo, melhoria do desempenho financeiro e também pela necessidade de mão de obra. Já o Hotel $\mathrm{F}$ (independente) o terceirizou somente pela falta de estrutura física. Inclusive o entrevistado cita que tal terceirização não seria concretizada caso houvesse espaço físico necessário para um estacionamento próprio.

\footnotetext{
${ }^{6}$ Entrevista realizada em 26/10/2010 com um profissional do setor hoteleiro. Atua no segmento há 16 anos. Atuou na gerência da área de Alimentos e Bebidas de um hotel de rede internacional na cidade de Curitiba. Foi gerente de uma empresa de consultoria na área de hotelaria. Atualmente é Gerente Geral de um hotel no estado de São Paulo.

${ }^{7}$ Id.
} 
Observa-se que a terceirização da panificação é citada apenas pelos hotéis independentes. Possivelmente os entrevistados desses hotéis consideram-na uma terceirização por haver a necessidade de fornecimento diário de itens para o café da manhã e em horários definidos, questões que podem ser estabelecidas em um contrato. Desse modo, a panificação é caracterizada uma terceirização pelos entrevistados.

Também nota-se que os serviços de contabilidade e serviços jurídicos foram citados como terceirizados somente pelo Hotel E. O Hotel F, durante a entrevista, faz um comentário que remete à existência de um contador que presta serviços para o hotel. Entretanto, não o cita como um serviço terceirizado. Assim, percebe-se que não há um entendimento claro a respeito da terceirização por parte dos gestores de hotéis independentes, sendo alguns dos serviços caracterizados como terceirização por uns e por outros não.

A terceirização da manutenção foi realizada somente pelo Hotel C. Conforme enfatizado pelo entrevistado, essa terceirização foi pioneira em Curitiba, e o hotel realizou essa primeira tentativa, mesmo sem existir empresas em Curitiba especializadas em manutenção do segmento hoteleiro. Possivelmente essa falta de fornecedores especializados desmotiva a terceirização por outros hotéis.

Verifica-se também que somente o Hotel A terceiriza a mão de obra extra, o monitoramento de internet e a segurança alimentar. A terceirização da segurança foi citada apenas pelo Hotel D. Já o suporte de informática é terceirizado apenas pelo Hotel $\mathrm{E}$.

A partir da análise comparativa dos motivos para a terceirização, observa-se que o custo é um motivo em destaque, citado por todos os hotéis entrevistados como razão para a terceirização. Diversos autores afirmam que a terceirização pode contribuir para a redução de custos (Bolat \& Yilmaz, 2009; Espino-Rodríguez \& Padrón-Robaina, 2005; Gilley \& Rasheed, 2000), seja pela obtenção de economias de escala (Lei \& Hitt, 1996) ou pela redução de capital investido em equipamentos, melhoria de processos, mão de obra etc. (Gilley \& Rasheed, 2000; Brasil, 1993, Bettis et al., 1992).

Em particular, como já mencionado, é notável a existência de uma concordância entre os gestores dos hotéis entrevistados, de que o custo é aspecto fundamental na decisão da terceirização da lavanderia. Mostra-se em destaque também a necessidade de mão de obra e a necessidade de mão de obra especializada, motivos citados por cinco dos seis hotéis entrevistados.

Três hotéis citaram o acesso à tecnologia e ao conhecimento como sendo um motivo para a terceirização, o que confirma as afirmativas de autores como Espino-Rodríguez e PadrónRobaina (2004) e Prado e Takaoka (2001) no que tange ao acesso facilitado a tecnologias e a recursos complementares de alta qualidade, possibilitado pela terceirização.

A existência de fornecedor especializado foi mencionada por três hotéis, um de rede internacional, um de rede nacional e outro independente. Assim, os resultados parecem apontar que as empresas tendem a terceirizar quando há a possibilidade de utilização das capacidades de profissionais especializados, como sugerem Kakabadse e Kakabadse (2000). 
A melhoria do desempenho financeiro foi citada como motivo da terceirização por dois hotéis, ambos pertencentes à rede, sendo um de rede internacional e outro de rede nacional. De acordo com Gilley e Rasheed (2000) essa melhoria do desempenho financeiro pode estar associada a outros aspectos, tais como o aumento do foco da organização nas suas competências essenciais, melhoria da qualidade dos serviços e a redução de custos.

A qualidade também foi mencionada como motivo da terceirização por dois hotéis pesquisados, um deles de rede internacional e o outro independente. $\mathrm{O}$ aspecto da melhoria da qualidade é discutido por Espino-Rodríguez e Padrón-Robaina (2004). Os autores afirmam que existe uma maior propensão em terceirizar quando as empresas percebem que podem melhorar a qualidade das suas operações por meio da terceirização.

O porte do hotel também foi citado por dois hotéis, sendo um deles independente e o outro pertencente à rede nacional. O hotel de rede nacional cita que o restaurante foi terceirizado em função do porte do hotel, já que isso influencia no volume de vendas de almoços, jantares e coffee-breaks. Já o hotel independente menciona que o porte do hotel influenciou na decisão da terceirização de três serviços, o que mostra que o porte do hotel é um aspecto que inviabiliza a realização de serviços internamente.

Assim, observa-se que os hotéis pesquisados de rede internacional não são motivados a terceirizar devido o porte do hotel. Normalmente são hotéis de maior porte, e, por pertencer a uma grande rede, possuem serviços internos que hotéis independentes e de pequeno porte não tem condições financeiras de mantê-lo internamente, assim como não seria viável manter uma equipe de funcionários especializados para prestar serviços somente para um hotel.

Os demais motivos (alta demanda, categoria do hotel, exigência do mercado, experiência da rede, foco nas competências essenciais, golpes e questões tributárias) foram, cada um, citados por apenas um dos hotéis entrevistados.

Os resultados parecem confirmar a relação entre valor estratégico do recurso e a terceirização, conforme mencionado no estudo de Espino-Rodríguez e Padrón-Robaina (2005). De acordo com os casos estudados, o valor estratégico do recurso parece influenciar nos relacionamentos entre hotel e empresa terceirizada. Observa-se que quanto menor o valor estratégico do recurso, menor é a preocupação dos hotéis em estabelecer relacionamentos mais próximos (estratégicos), como por exemplo, a terceirização da lavanderia. Por outro lado, quando um recurso possui certo valor estratégico, os hotéis estudados se preocupam em estabelecer uma relação mais próxima, considerando-os parceiros, a fim de garantir a prestação de serviços nos padrões de qualidade desejados, bem como melhorar a capacidade de negociação dos valores estabelecidos em contrato.

\section{PROCESSO DE TERCEIRIZAÇÃO}

A análise do processo de decisão da terceirização fez-se necessária para compreender como a terceirização é administrada nos hotéis em Curitiba. Tendo em vista que a capacidade 
dinâmica pode estar relacionada à maneira pela qual os gestores a administram, a análise do processo de terceirização revelaria os aspectos que poderiam ser caracterizados importantes para a obtenção e manutenção de vantagem competitiva pelas organizações estudadas.

A partir da análise dos casos, foi possível identificar as etapas do processo de terceirização de cada caso, bem como a maneira pela qual a terceirização é administrada. Todos os processos de terceirização são descritos e representados ao longo do capítulo 4. A comparação dos processos de terceirização adotados pelos seis hotéis entrevistados permitenos chegar às seguintes considerações.

Apesar de pertencerem a uma mesma rede hoteleira, os processos de terceirização obtidos do Hotel $A$ e Hotel $B$ apresentam diferenças com relação às etapas que compõem o processo de terceirização. Não se pode descartar a possibilidade de que realmente haja diferenças no processo de decisão adotado por cada hotel da rede, uma vez que são dois hotéis de categorias diferentes e bandeiras diferentes. No entanto, deve-se considerar a possibilidade da existência de percepções diferentes de cada gestor com relação ao processo de terceirização, refletidas nas declarações concedidas na entrevista. Há também de se pesar a predisposição do entrevistado no nível de detalhamento da realidade do hotel, o que pode resultar em processos visualmente mais simplificados e outros mais complexos.

Há uma nítida diferença entre o processo de terceirização de hotéis pertencentes a redes e hotéis independentes. A tomada de decisão de terceirização de serviços e atividades nos hotéis de rede nacional e internacional ocorre de maneira sempre formal. Nota-se que há procedimentos e regras definidas, assim como a participação de cada ator no processo, sendo bem definido em quais etapas cada um participa. Acrescenta-se a isso o uso de procedimentos formalizados, tais como o registro do histórico do terceirizado e reuniões formais com o responsável.

Notam-se também diferenças na etapa da implantação do serviço terceirizado. Nos hotéis independentes essa etapa se confunde com a gestão da terceirização. Já em hotéis pertencentes a redes, internacionais ou nacionais, a etapa da implantação é bem definida, sendo realizadas ações específicas de integração e adaptação do funcionário da empresa terceirizada ao hotel.

Uma comparação dos tipos de serviços terceirizados pelos hotéis contribui para a análise desse aspecto. Os serviços terceirizados pelos hotéis independentes são serviços em que normalmente não há a necessidade do funcionário do terceiro permanecer dentro do hotel. Devido a isso, não há a necessidade nem preocupação do hotel na integração desse funcionário às rotinas e cultura do hotel, uma vez que eles não estarão diretamente em contato com os hóspedes. A percepção do hóspede, nesses casos, será meramente a respeito da qualidade do produto e serviço prestado pelo terceirizado, e não diretamente no atendimento.

Por outro lado, nos hotéis de rede, serviços como a área de alimentos e bebidas, o estacionamento e o Business Center, são serviços que o terceirizado prestará diretamente ao hóspede, representando a imagem do hotel. Assim, a percepção do cliente quanto à qualidade 
desses serviços estará diretamente relacionada à qualidade dos serviços do hotel como um todo. Possivelmente, em função disso, as redes hoteleiras tem maior preocupação na integração dos funcionários do terceirizado, realizando programas formais de integração e ações que fazem com que o funcionário terceiro esteja alinhado ao padrão de atendimento e à cultura do hotel. Como afirmam Hemmington e King (2000) quando um terceiro assume atividades em que as operações são estreitamente próximas ao hotel, o compartilhamento da cultura organizacional entre as partes torna-se particularmente importante.

Ao fim, pode-se verificar que a terceirização corresponde a uma estratégia que pode ser entendida como uma parte da capacidade dinâmica, pois por meio da terceirização os hotéis estudados alcançaram novas configurações de recursos, a partir da integração dos recursos da empresa terceirizada ao hotel. Portanto a terceirização pode ser entendida como um processo de integração de recursos externos à empresa, complementado os recursos que a mesma possui, para a obtenção/manutenção da sua vantagem competitiva no mercado.

Porém, não só a terceirização em si pode corresponder à capacidade dinâmica, isto é, ela pode também estar no relacionamento entre os diversos atores envolvidos no processo decisório. A comunicação entre os atores distintos possibilita a transferência de conhecimento entre eles. Nos hotéis estudados, o relacionamento ocorre tanto verticalmente (Gerente/Diretoria; Supervisores/Gerentes; colaboradores/Supervisores) quanto horizontalmente (entre Diretores, Gerentes e Supervisores). O relacionamento também ocorre com atores externos à organização, havendo compartilhamento de informações entre gestores de hotéis.

Especialmente nos hotéis pertencentes a redes, internacionais e nacionais, esse relacionamento vertical parece desempenhar um importante papel na gestão das terceirizações, uma vez que a Diretoria reúne conhecimentos relacionados a diversas áreas e de realidades de diferentes hotéis. Já nos hotéis independentes, observa-se uma importância nos relacionamentos desenvolvidos com outros hotéis, na qual há uma troca de experiências entre eles.

\section{CONSIDERAÇÕES FINAIS}

O presente estudo buscou analisar as terceirizações de serviços e atividades realizadas pelos hotéis, na tentativa de compreender a capacidade dinâmica nas organizações hoteleiras. Para tanto definiu-se como objetivo central analisar os motivos que levaram os hotéis à decisão da terceirização, bem como estudar o processo de decisão da terceirização.

A partir dos dados coletados foram identificados 14 serviços terceirizados pelos seis hotéis pesquisados. Destes, apenas a lavanderia é terceirizada por todos os hotéis, e o Business Center terceirizado por três hotéis. O restaurante e o frigobar são terceirizados apenas por dois hotéis, ambos pertencentes a rede nacional. Apenas os hotéis independentes pesquisados terceirizam a panificação. Já o estacionamento é terceirizado por um hotel independente e outro de rede internacional. A manutenção foi terceirizada apenas pelo Hotel C. Por sua vez, a 
mão de obra extra, o monitoramento de internet e a segurança alimentar foram terceirizados somente pelo Hotel A. Apenas o Hotel E terceiriza os serviços de contabilidade, os serviços jurídicos e o suporte de informática. E a segurança é terceirizada apenas pelo Hotel D.

Quanto às mudanças ocorridas nas terceirizações durante o período estudado (segundo objetivo específico), verificou-se que nos hotéis $A, C$ e $E$ houve novas terceirizações de serviços/atividades no período. Já nos demais hotéis a quantidade de serviços terceirizados permaneceu constante. Também notou-se em apenas um dos casos estudados a desistência do hotel quanto à terceirização, ocorrendo então o retorno da atividade para o hotel. O motivo da decisão foi influenciada principalmente pela inexistência de fornecedor especializado.

Ao analisar os motivos que levaram à terceirização dos serviços e atividades (terceiro objetivo específico), observou-se que, de um modo geral, a terceirização foi motivada principalmente por questões mais relacionadas aos aspectos financeiros, tais como a redução de custos, a melhoria do desempenho financeiro e a necessidade de contratação de mão de obra, seja ela especializada ou não.

Apesar disso, outros aspectos também se destacam como motivadores da terceirização, tais como a existência de fornecedor especializado, a falta de estrutura física e o acesso à tecnologia e ao conhecimento. Assim, os dados apontam que alguns dos hotéis estudados parecem adotar uma posição estratégica quanto à terceirização, buscando fornecedores externos especializados para a realização de serviços/atividades específicas, às quais o hotel não teria condições de realizar sozinho.

Também foram mencionados os seguintes motivos da terceirização: a alta demanda, a categoria do hotel, a exigência do mercado, a experiência da rede, o foco nas competências essenciais, os riscos associados a golpes, o porte do hotel, a melhoria da qualidade e as questões tributárias.

Ainda, nos casos estudados, existem diferenças significativas no processo de terceirização entre os tipos de hotéis. Hotéis pertencentes a redes, tanto nacionais como internacionais, adotam um processo formalizado com definições claras das atribuições de cada nível hierárquico nesse processo, além do envolvimento da Diretoria da rede no processo decisório.

De modo contrário, hotéis independentes adotam um processo de decisão mais informal, não sendo utilizados procedimentos tão formais na decisão. A comunicação entre os supervisores, Gerente e Diretor é realizada por meio de conversas informais, sem a realização de reuniões. Além disso, a gestão da terceirização é realizada de maneira informal, com conversas diretas com o funcionário do terceirizado. Não são citadas reuniões formalizadas com o responsável do terceirizado para a resolução de problemas, repasse de informações ou de elogios, como é feito nos hotéis pertencentes a redes. A informalidade mencionada aqui não se refere à inexistência de contrato de terceirização, já que o contrato é requisito na consideração de um serviço terceirizado. Refere-se à falta de procedimentos e rotinas formalizadas.

Finalmente não foram identificadas mudanças nas terceirizações em decorrência da crise financeira de 2008 e a gripe H1N1. Os impactos causados pelos dois eventos foram no 
desempenho do hotel, principalmente na redução da demanda e cancelamento de reservas. Apesar disso, o Hotel B menciona que a terceirização contribuiu para a gestão dos prejuízos sentidos em 2009.

\section{REFERÊNCIAS}

Bardin, L. (2009) Análise de Conteúdo. Lisboa: Edições 70.

Bolat, T.; Yilmaz, Ö. (2009) The relationship between outsourcing and organizational performance: is it myth or reality for the hotel sector? International Journal of Contemporary Hospitality Management, 21(1), 7-23.

Brasil, H. G. (1993) A empresa e a estratégia da terceirização. Revista de Administração de Empresas. São Paulo, 33(2), 6-11.

Elmuti, D. (2003). The perceived impact of outsourcing on organizational performance. MidAmerican Journal of Business, 18(2), 33-41.

Espino-Rodríguez, T. F., \& Gil-Padilla, A. M. (2005). Determinants of information systems outsourcing in hotels from the resource-based view: an empirical study. International Journal of Tourism Research, 7, 3547.

Espino-Rodríguez, T. F., \& Padrón-Robaina, V. (2004). Outsourcing and Its impact on operational objectives and performance: a study of hotels in the Canary Islands. Hospitality Management, 23, 287-306.

Espino-Rodríguez, T. F., \& Padrón-Robaina, V. (2005). A resource-based view of outsourcing and its implications for organizational performance in the hotel sector. Tourism Management, 26(5), 707-721.

Gilley, K. M., \& Rasheed, A. (2000). Making more by doing less: an analysis of outsourcing and its effects on firm performance. Journal of Management, 26(4), 763-790.

Hemmington, N., \& King, (2000) C. Key dimensions of outsourcing hotel food and beverage services. International Journal of Contemporary Hospitality Management, 12(4), 256-261.

HVS Brasil. (2010) brasileira 2009/2010. São Paulo, 2010. Recuperado de http://pt.hvs.com/Library/Articles/?cat=7

Lam, T., \& Han, M. X. J. (2005). A study of outsourcing strategy: a case involving the hotel industry in Shanghai, China. Hospitality Management, 24, 41-56.

Lamminmaki, D. (2011). An examination of factors motivating hotel outsourcing. International Journal of Hospitality Management, 30, 963-973.

Lei, D., \& Hitt, M. (1995). Strategic restructuring and outsourcing: the effect of mergers and acquisitions and LBOs building firm skills and capabilities. Journal of Management, 21(5), 835-859.

Leite, J. C. (2004) Terceirização em informática. São Paulo: Makron Books.

Lilly, J. D. et al. (2005). Outsourcing the human resource function: environmental and organizational characteristics that affect HR performance. Journal of Business Strategies, 22(1), 55-73.

Prado, E. P. V., \& Takaoka, H. (2001). Os fatores que motivam a adoção da terceirização da tecnologia de informação: uma análise do setor industrial de São Paulo. Trabalho apresentado no Encontro da Associação Nacional dos Programas de Pós-Graduação em Administração.

Prahalad, C. K., \& Hamel, G. (1990). The core competence of the corporation. Harvard Business Review, 115. 
Quinn, J. B. (1999). Strategic outsourcing: leveraging knowledge capabilities. Sloan Management Review, 40(4), 9-21.

Rodríguez-Díaz, M., \& Espino-Rodríguez, T. F. (2006). Developing relational capabilities in hotels. International Journal of Contemporary Hospitality Management, 18(1), 25-40.

Teece, D. J. (2007). Explicating dynamic capabilities: the nature and microfoundations of sustainable enterprise performance. Strategic Management Journal, 28(13), 1319-1350.

Teece, D. J., Pisano, G., \& Shuen, A. (1997). Dynamic capabilities and strategic management. Strategic Management Journal, 18(7), 509-533.

Artigo recebido em: 25/01/2013.

Artigo aprovado em: 30/03/2013. 